\title{
Examination of combined ferry on the dynamic work
}

\author{
Dmitry Tryapkin ${ }^{1, *}$ and Yuriy Tryapitsin ${ }^{1}$ \\ ${ }^{1}$ Far Eastern State Transport University, Serysheva st., 47, 680021, Khabarovsk, Russia
}

\begin{abstract}
The results of the dynamic characteristics experiments and calculation of combined crossing dynamic coefficient are given. The experiments were carried out by temporal automobile load with using measuring rated complex. Agreement of calculation results and test results is obtained.
\end{abstract}

\section{Introduction}

Dynamic processes in road constructions of traffic way of the combined crossings (ice crossings, reinforced with metal pontoon structures made of double-seat ferries) are its natural reaction to a short-term impact of the wheels of moving vehicles. In the process of operation its individual elements are exposed to different degrees of intensity that characterized by their different terms of service.

The main tasks during the survey and testing the bridges are to determine the bearing capacity of a bridge span and other bridge elements, and to estimate the dynamic characteristics. The tests by temporal mobile loads are carried out in two modes: static [6,7] and dynamic.

Dynamic tests are conducted to detect the values of the dynamic effects generated by real mobile loads, to determine the basic dynamic characteristics of structures - frequencies and forms of natural vibrations, the dynamic stiffness of the structure, characteristics of damping oscillations. There is no unified engineering methodology that allows to calculate the dynamic coefficient of the combined crossing in the normative documents. The goal of this work is to develop this methodology.

The ice crossing, reinforced with metal pontoon structures made of the double-seat ferries (hereinafter, the combined ferry) across the Ussuri river, located near the village of Pokrovka of the Bikin district in the Khabarovsk region on the border with China was taken as an object of examination.

Combined crossing is arranged by directing and subsequent freezing of the metal pontoon structures of the Chinese-made floating road bridge made floating road bridge in the ice cover of the river immediately after the end of the freezing up. In the lengthwise direction, span structures on double-decked ferries are combined by the hinge-console system with coupling devices in the form of vertical sleeve piece with a horizontal

* Corresponding author: dmitry.tryapkin@yandex.ru 
retractable dowel on the pin (bolted joints), forming a ribbon bridge. In each span across the bridge the beams are united by three cross beams in a step of $2.8 \mathrm{~m}$ and a height equal to the height of the main beams and by four half the height supporting cross beams placed between them (step $1.4 \mathrm{~m}$ ). The dimensions of the belts of high cross beams are $1 \times 20 \mathrm{~cm}$, of the supporting cross beams are $1 \times 10 \mathrm{~cm}$. The carriageway of the bridge is made of a 1 $\mathrm{cm}$ thick metal sheet and the main span beams are rigidly connected with two pontoons. Length of a cantilever of main beams from pontoons $1.0 \mathrm{~m}$. Transition part - single-console (ramp), based on a natural base.

\section{Calculation of the dynamic coefficient of the combined crossing}

Determination of dynamic coefficient is realized according to [1], when the thickness of the ice cover $\mathrm{h}=83 \mathrm{~cm}$, width $\mathrm{B}=15 \mathrm{~m}$ and the speed of the vehicle passage $v=10 \mathrm{~km} / \mathrm{h}$.

Coefficient of the base

$$
k=\frac{\gamma \cdot F}{L}
$$

where $\gamma=9,81 \mathrm{kN} / \mathrm{m}^{3}$ - the volumetric weight of water; $\mathrm{F}=104,2 \mathrm{~m}^{2}$ - area of the waterline; $L=19 m-$ the span of the river part.

Then

$$
k=\frac{\gamma \cdot F}{l}=\frac{9,81 \cdot 104,2}{19}=53,8 \mathrm{kN} / \mathrm{m}^{3}
$$

$\mathrm{E}=5880 \mathrm{MPa}-$ modulus of elasticity of the ice cover;

$I=\frac{B h^{3}}{12}=\frac{15 \cdot 83^{3}}{12 \cdot 100^{3}}=0,71473375 \mathrm{~m}^{4}$ - axial moment of inertia of the cross sectional area of the plate.

The elastic characteristic of the combined crossing based on the bending

$$
\alpha_{1}=\sqrt[4]{\frac{k}{4 E I}}
$$

where $E I=588 \cdot 100^{2} \cdot 0,71473375=4202634,45 \mathrm{kNm}^{2}$ - the stiffness of the plate (ice layer);

$m=\frac{0,5 \cdot \gamma \cdot K_{m} \cdot B^{2}}{g}=\frac{0,5 \cdot 9,81 \cdot 0,5527 \cdot 15^{2}}{9,81}=62,1825 \mathrm{kN} / \mathrm{m}^{3}$ - mass per unit length of the pontoon bridge due to entrained water,

Here $K_{m}=0,44+0,089 \frac{\mathrm{L}}{\mathrm{B}}=0,44+0,089 \frac{19}{15}=0,5527[4,5]$.

Then

$$
\alpha_{1}=\sqrt[4]{\frac{k}{4 E I}}=\sqrt[4]{\frac{53,8}{4 \cdot 4202634,45}}=0,04231 / \mathrm{m}
$$

From which dynamic coefficient 


$$
1+\mu=\frac{\alpha_{1}}{\alpha}=\frac{\alpha_{1}}{\sqrt{\alpha_{1}^{2}-\frac{m v^{2}}{4 E I}}}=\frac{0,0423}{\sqrt{0,0423^{2}-\frac{62,1825 \cdot 2,78^{2}}{4 \cdot 4202634,45}}}=1,01
$$

\section{The methodology of dynamic tests}

Dynamic tests of the combined crossing were conducted to determine the actual dynamic characteristics, according to para 6.15 SP 79.13330.2012 [2]:

- Determination of the dynamic coefficient at various speeds of the temporal load;

- Determination of the oscillations of a bridge span's period;

- Determination of the logarithmic damping decrement.

For excitation of dynamic oscillations of the combined crossing there has been used loaded vehicle on the basis of car IVECO, KAMAZ and buses DAEWOO, passing the combined crossing at speeds up to $10 \mathrm{~km} / \mathrm{h}$. The tests were performed 3 times, with simulation of the "threshold" and without it, alternately from the Pokrovka (Russia) and from the city Zhaohe (China).

When conducting dynamic tests the vibrograms of oscillations of the combined crossing were recorded simultaneously monitored in span No. 3 and on the pontoon No. 6 by set of the measuring complex "Phase".

In the process of the crossing's dynamic tests the characteristics were measured by sensors of "Phase" system. Each sensor was interrogated with a frequency of $100 \mathrm{~Hz}(100$ measurements / sec), that allow to analyze oscillatory processes from frequency 0 to $50 \mathrm{~Hz}$. Configuration plan of sensors similar to the static examination [6,7].

During the measuring of dynamic characteristics of the combined crossing highfrequency components of the fluctuations were determined, then as the result of Fouriertransformation the basic harmonics of oscillations were educed, and the basic harmonic of oscillations was analyzed, that determine the logarithmic decrement of damping. On the monitor of the complex "Phase" vibrograms of oscillations are displayed, which were processed by computer complex "Phase" in automatic mode with outgiving the values of the dynamic coefficient, period of oscillation, the logarithmic decrement of damping, as well as quasi-static curve of the beam deflection, which can estimate the nature of the oscillatory process and measure the value of the static deflection.

According to SNiP 2.05.03-84* p. 2.22 [3] normative dynamic coefficient for spans in length $\mathrm{L}=13 \mathrm{~m}$ (the distance between the axes of the floating supports), $\mathrm{L}=33,32 \mathrm{~m}$ (length of influence line of reaction a floating piers) is determined by the formula:

$$
1+\mu=1+\frac{15}{37,5+\lambda}
$$

And, accordingly, is $-1+\mu=1,4$ - for beams; 1,2 - for combined crossing. The same value of the dynamic coefficients gives SP 35.13330.2011. Actualized version of SNiP 2.05.03-84*.

In fig. 1.-2. the first and the last vehicle passage on the bridge are presented, without "threshold", in the third span and with the "threshold". 


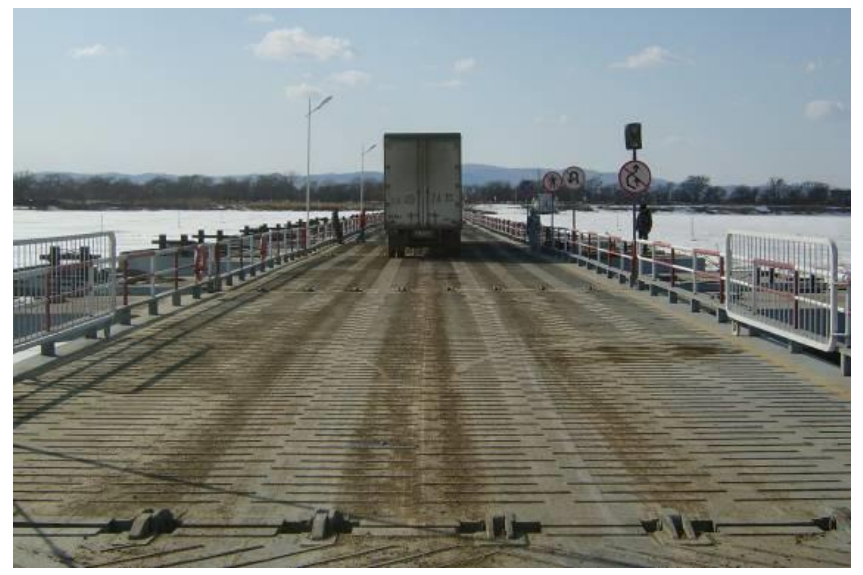

Fig. 1. Configuration of the first loaded vehicle passage.

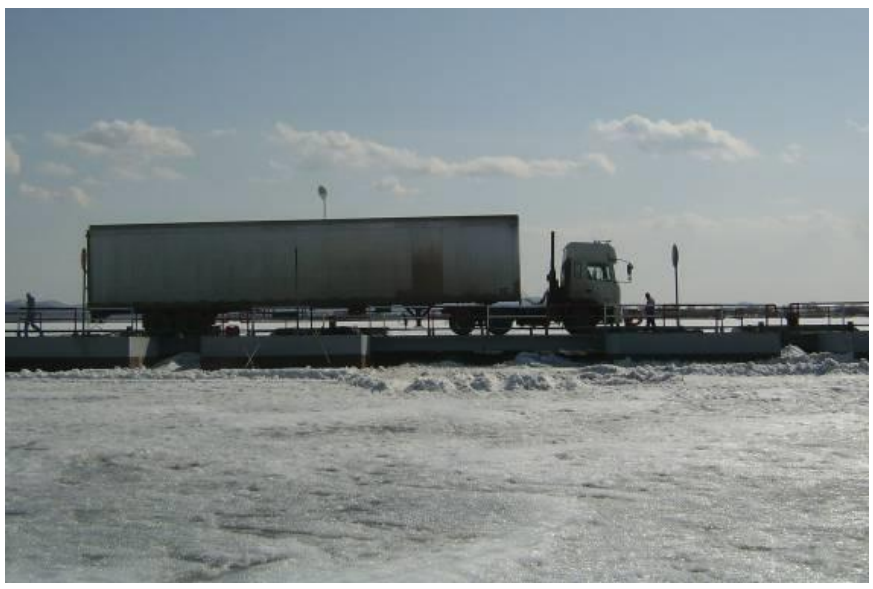

Fig. 2. Configuration of the loaded vehicle passage with the "threshold" and in the span.

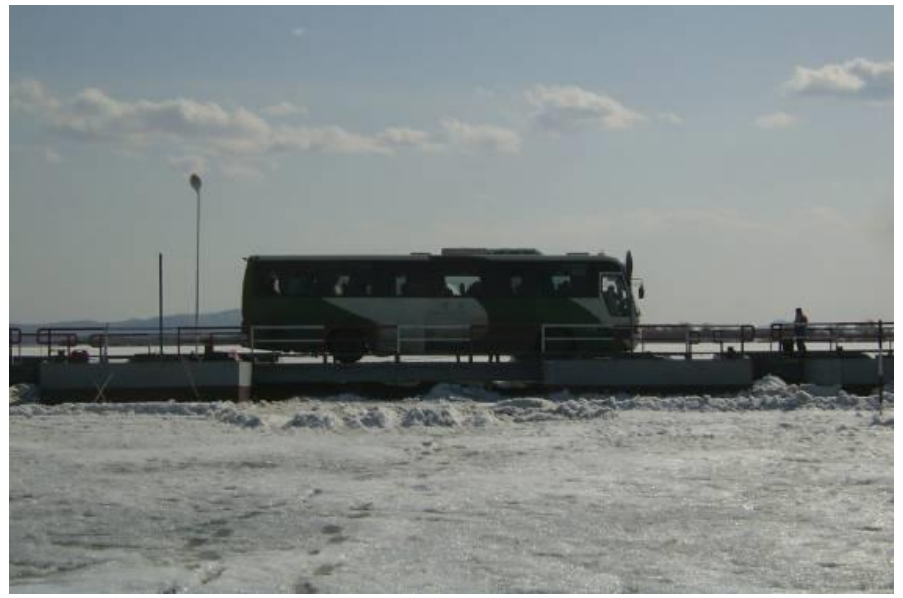

Fig. 3. Bus arrival scheme.

In fig.4. vibrogram fluctuations in the beam No.10 in the third span and pontoon No. 6 (ice cover) in the first, second, third and fourth span are shown. 

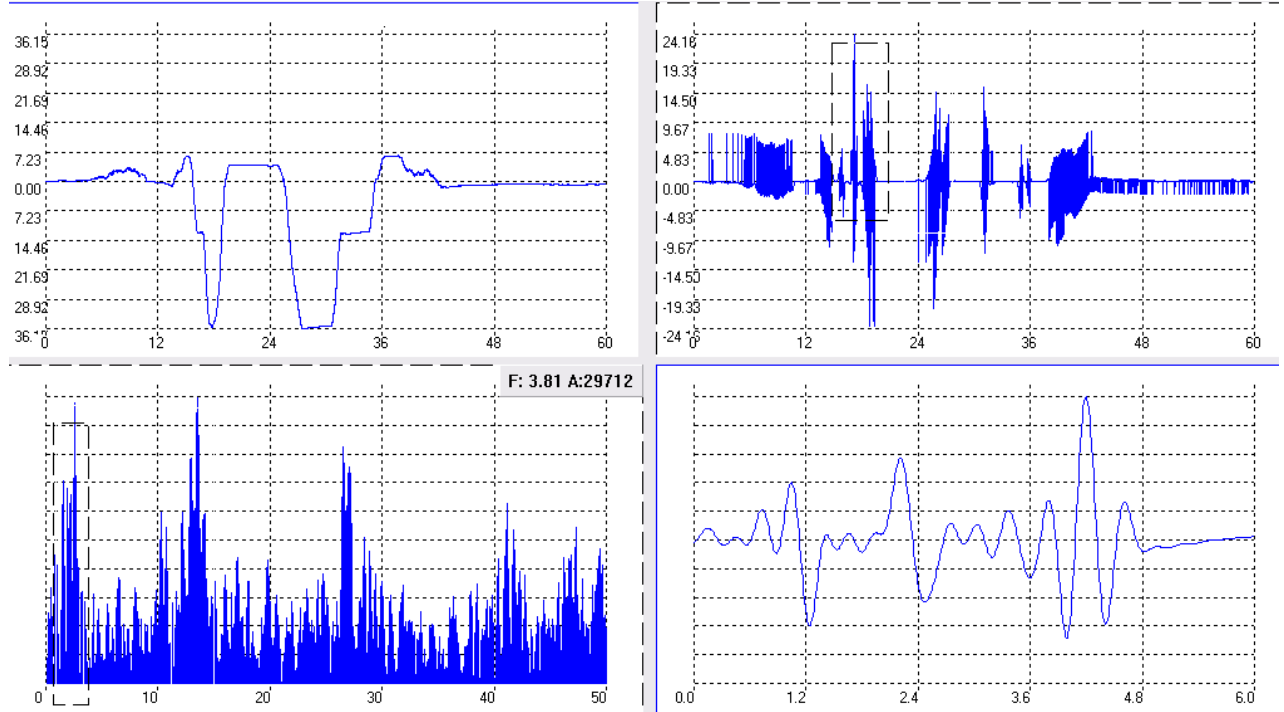

Fig. 4. The program window with vibrogram of the beams No. 10 of the span No. 3, without "threshold" in. IVECO passage from Pokrovka.

Next, on a special program the calculation of the main dynamic characteristics of the being tested spans (beam No.10 of the span No.3 or pontoon No.6) and ice cover was conducted. The maximum deflection was $16.9-27,8 \mathrm{~mm}$. The maximum amplitude amounted to $34,5-$ $46,8 \mathrm{~mm}$. The frequency spectrum of oscillations has a pronounced maximum of its vibrations. Dynamic coefficient is 1.02 , the damping decrement $-0,25-1,25$.

\section{Conclusion}

The nature of work of the spans from passing temporal load coincides with the work of the ice cover (the same deflections, dynamic coefficients, the damping decrements). Ice cover and pontoon structures work together.

The measurements were conducted with the passage of different types of loads on the bridge. The natural frequency is $2.7-3 \mathrm{~Hz}$, that corresponds to the period of oscillation of $0.33-0.37$ seconds. i.e., the period of oscillations is not included in the "undesirable" interval of 0.4-0.6 sec.

The dynamic coefficient during the test coincided with the theoretical value amounted 1.01 against regulatory 1,2. Offered methodology of determination of the combined crossing's dynamic coefficient has experimental confirmation.

\section{References}

1. V.I. Telov, Pontoon bridges and ferries (Monograph, 2006)

2. Russian State Standard SP 79.13330.2012

3. Russian State Standard SNIP 2.05.03-84*

4. Classification and construction of pontoon bridges. Interim guidance (Moscow 2005)

5. V.I. Telov, I.M. Kanukov, Pontoon bridges, ferry and ice crossings (1978)

6. U.V. Tryapitsyn, D.A. Tryapkin, Vestnik PNU 3(30), 149-158 (2013)

7. U.V. Tryapitsyn, D.A. Tryapkin, Vestnik PNU 2(33), 103-112 (2014) 